\title{
INFLUENCE OF ATMOSPHERIC CHARACTERISTICS ON THE DIFFUSION AND TRANSPORT OF HARMFUL EMISSIONS
}

\author{
G.Y Todorova
}

Sofia University "St.Kliment Ohridsky", Faculty of Physics, Sofia, Bulgaria

\begin{abstract}
Recently used modelling of industrial air emissions does not take into consideration the chemical conversion of various pollutants in the atmosphere. This can lead to incorrect assumption about concentrations and composition of waste gases near the recipient, especially in highly polluted urban areas. This is particularly valid for gas emissions being subject to conversion between their points of emitting and final destination. As a result of dispersion modelling of the diffusion, formation and correlation of waste gases emissions from point sources depending on the ambient ozone concentration, ambient air temperature and waste gases temperature, I came to the conclusion that the physical and chemical characteristics of the ambient air do influence the formation of secondary pollutants at a distance from the emission source. When performing environmental evaluation of certain equipment being a source of air emissions, we should take into consideration the pollutant's behaviour in relation to the specific environmental features.
\end{abstract}

\section{Introduction}

Principal pollutants which are emitted from industry and are chemically converted in the atmosphere are sulphur oxides (SOx), carbon oxides $\left(\mathrm{CO}_{\mathrm{x}}\right)$, nitrogen oxides $\left(\mathrm{NO}_{\mathrm{x}}\right)$ and hydrocarbons. They participate in photochemical reactions with the ozone, thus changing on one hand their structure and influencing the troposphere ozone concentrations on the other hand. Gases' diffusion is strictly limited by wind direction and speed. Humidity and air temperature, as well as transitory solar radiation define the rate and direction of various chemical and photochemical transformations among the atmospheric gases and the emitted ones.

We can take into account these factors after applying dispersion modelling for the individual pollutants. Modelling results give information about the cases' behaviour in particular geographical and climate conditions, as well as about the presence, nature and concentration of background

\section{contamination.}

Transfusion, diffusion and pattern of waste gases is predicted by manipulating data for the chemical composition of the air, its humidity and temperature, as well as wind speed and direction.

\section{Materials and Methods}

In order to specify the relationship between the environmental conditions and the formation and diffusion of pollutants emitted by point sources, I used a mathematical model for dispersion modelling. The model is developed and tested by the European Commission for predicting transport, atmospheric diffusion, physical and chemical conversion, optical effects and deposition of waste gases after discharge from the sources. Model predicts the spatial distribution and chemical conversion of nitrogen oxide (NO) to nitrogen dioxide and oxides of sulphur and nitrogen (SOx; NOx) to sulphates and nitrates. The environmental 
specifics are defined by the input data necessary for starting up the model, including: air temperature and humidity, wind speed and direction, intensity of sun radiation, ambient concentrations of sulphur and nitrogen oxides, tropospheric ( ambient) ozone, temperature of waste gases etc.

The model is based on several fundamental equations as follows:

\section{Initial Diffusion in a Buoyant Plume:}

$\chi=\frac{2.94 Q}{(\Delta h)^{2} u}$,

where:

$h$ is the plume height above the stack;

$u$ is the wind speed;

$Q$ is the emission, and

$X$ is the pollutant concentration in the plume centerline.

\section{Plume Rise:}

The final plume rise in PLUVUE II is calculated using the modified plume rise formulae of Briggs $[3 ; 4 ; 5]$ defined as follows:

$\Delta h=$ minimum of $\left\{\begin{array}{c}2.6(F /(u s))^{1 / 3} \\ 5 F^{1 / 4} s^{-3 / 8}\end{array}\right.$.

where:

$S$ is a stability parameter;

$F$ is a coefficient defined by the mass stream, ambient air temperature and gravity acceleration.

\section{Gaussian Plume Diffusion Prediction:}

After the plume has achieved its final height (about $1 \mathrm{~km}$ downwind), plume concentrations for uniform wind fields can be adequately predicted using a Gaussian model if the wind speed $\mathrm{u}$ at plume height $\mathrm{H}$ (or hs $+\Delta \mathrm{h}$, where hs is the stack height) and the rate of diffusion are known for the particular situation so that diffusion coefficients $(\sigma y, \sigma z)$ can be selected:

$$
\begin{aligned}
& \chi=\frac{Q}{2 \pi \sigma_{y} \sigma_{z} u} \exp \left[-\frac{1}{2}\left(\frac{y}{\sigma_{y}}\right)^{2}\right] . \\
& \left\{\exp \left[-\frac{1}{2}\left(\frac{H+z}{\sigma_{z}}\right)^{2}\right]+\exp \left[-\frac{1}{2}\left(\frac{H-z}{\sigma_{z}}\right)^{2}\right]\right\} .
\end{aligned}
$$

\section{Conversion of $\mathrm{NO}$ to $\mathrm{NO}_{2}$ :}

$\mathrm{NO}$ to $\mathrm{NO}_{2}$ conversion can be calculated from a simple set of three reactions

The first one is the thermal oxidation of $\mathrm{NO}$ to $\mathrm{NO}_{2}$ :

$2 \mathrm{NO}+\mathrm{O}_{2} \rightarrow 2 \mathrm{NO}_{2}$

The reaction with ozone affects the conversion of $\mathrm{NO}$ to $\mathrm{NO}_{2}$, too:

$K_{r}$

$\mathrm{NO}+\mathrm{O}_{3} \rightarrow \mathrm{NO}_{2}+\mathrm{O}_{2}$

The reaction is fast, with a rate as per $[10 ; 7 ; 11]$ at $25^{\circ} \mathrm{C}$.

The third reaction to conclude with, is the photolysis of $\mathrm{NO}_{2}$.

Its rate is defined by [10].

$$
K_{d}
$$

$\mathrm{NO}_{2}+h v \rightarrow \mathrm{NO}+\mathrm{O}$,

\section{Conversion of $\mathrm{SO}_{2}$ to $\mathrm{SO}_{4}{ }^{=}$and $\mathrm{NO}_{2}$ B $\mathrm{HNO}_{3}\left(\mathrm{NO}_{3}{ }^{-}\right)$:}

In clean background areas, the gaseous phase oxidation of $\mathrm{SO}_{2}$ and $\mathrm{NO}_{2}$ to sulphate aerosol and nitrate (nitric acid vapor) is primarily caused by the reaction of these species with $\mathrm{OH} \cdot$. Previous assessments of homogeneous (gaseous phase) oxidation of $\mathrm{SO}_{2}$ to sulphate estimated the proportion assignable to the reaction with hydroxyl to about $75 \%$ in clean atmospheres $[1 ; 6]$ and as low as $40 \%$ in polluted urban air [9]. However, later estimations place these values much higher. Most recently the rate constant has been measured at $8.1 \times 10^{-12}$ $\mathrm{cm}^{3} \mathrm{~mol}^{-1} \mathrm{~s}^{-1}[8]$.

In order to define the atmospheric conditions influence on the concentrations of emissions, mathematical model was started up with equal input data but different for the investigated parameter only.

The influence of ambient ozone concentrations was determined for $0.02 \mathrm{ppm}, 0.1$ ppm and $0.2 \mathrm{ppm}$. Destinations for which the results were generated include 1, 2.5, 5; $10,12.5$ and 15 kilometers from the emissions' source.

The influence of atmospheric temperature 


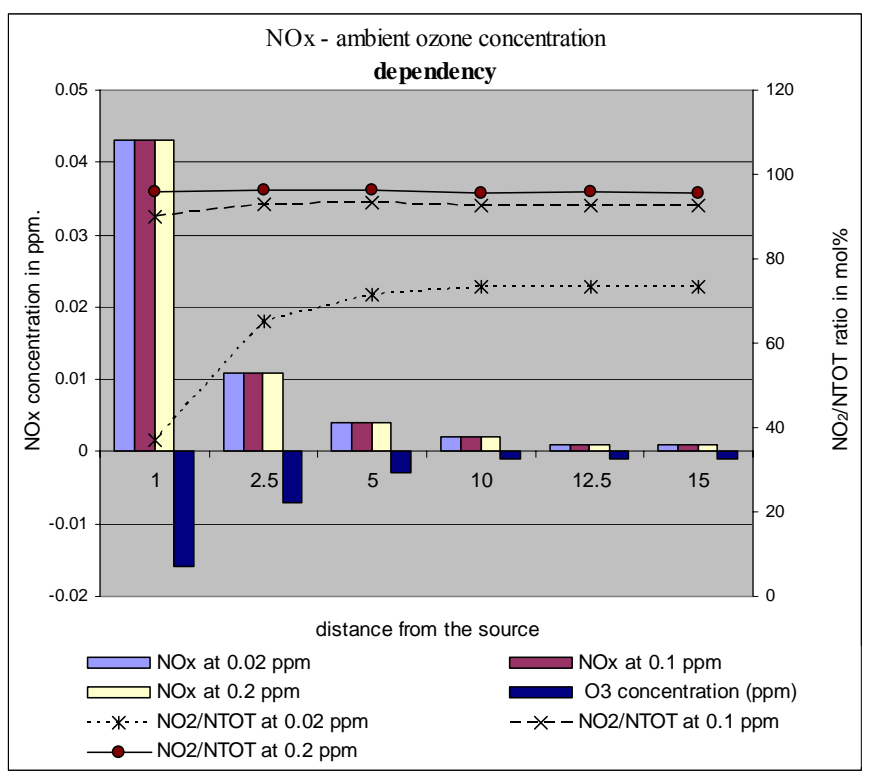

Fig. 1.

was determined for $-5,0,10$ and $25^{\circ} \mathrm{C}$.

The influence of waste gases temperature was determined for 500,1000 and $1500^{\circ} \mathrm{C}$.

Results from the analysis are presented on Figs. 1 - 5.

\section{Results and Discussion}

On Fig. 1 the influence of ambient ozone concentrations on the concentrations of nitrogen oxides is presented. The concentrations of NOx decrease with the distance from source. For each destination, there is not any influence of ozone on NOx quantity.

Rising ambient ozone concentrations lead to increased ratio of nitrogen dioxide to total nitrogen $\left(\mathrm{NO}_{2} / \mathrm{NTOT}\right)$ for any destination from the source. This increase is due to reaction between $\mathrm{NO}$ and $\mathrm{O}_{3}$ to form $\mathrm{NO}_{2}$, which is proved by the decrease of the two gases with time. Two gases are consumed in the reaction to produce nitrogen dioxide. After the $5^{\text {th }} \mathrm{km}$ the available quantity of $\mathrm{NOx}$ is depleted and the formation of $\mathrm{NO}_{2}$ is stabilized.

On Fig. 2, we observe a similar tendency, this time for increasing the nitrate/total nitrogen ratio as well as the sul- phate/total sulphur ratio $\left(\mathrm{SO}_{4}{ }^{-/ S T O T}\right)$. This tendency is valid with increasing distance from the source and ozone concentrations. As far as $\left(\mathrm{NO}_{3}{ }^{-}\right)$is formed in reaction between $\mathrm{NO}_{2}$ and $(\mathrm{OH} \cdot)$, when increasing the quantity of the dioxide, the concentration of nitrate rise up as well.

When defining the influence of ambient air temperature on the emissions composition dependence on the nitrate and sulfate ions was observed.

From Fig. 3 we can conclude that the concentration of ions depends on the distance from the source and on the temperature as well. The ratio $\left(\mathrm{SO}_{4}{ }^{-} / \mathrm{STOT}\right)$ and $\left(\mathrm{NO}_{3}{ }^{-}\right.$/NTOT) are increased for any destination and in relation to the temperature. The highest concentrations of nitrate and sulfate ions are observed at temperature $25^{\circ} \mathrm{C}$ followed by $0{ }^{\circ} \mathrm{C}, 10^{\circ} \mathrm{C}$ and $-5^{\circ} \mathrm{C}$. Both ions are formed when the corresponding oxides react with the hydroxyl radical $(\mathrm{OH} \cdot)$. This fact can explain the similar amplitudes of variation in ion concentrations with distance and air temperature. It seems that $\mathrm{OH} \cdot$ activity enhances depending on the temperature as follows: 


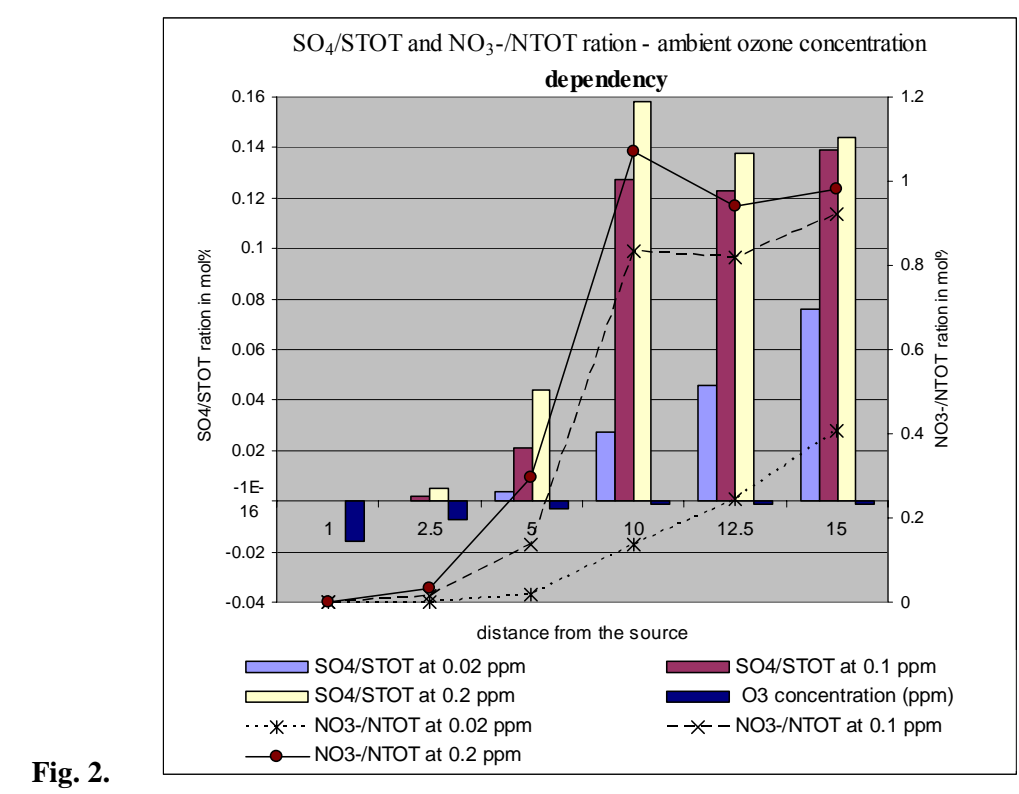

Fig. 2.

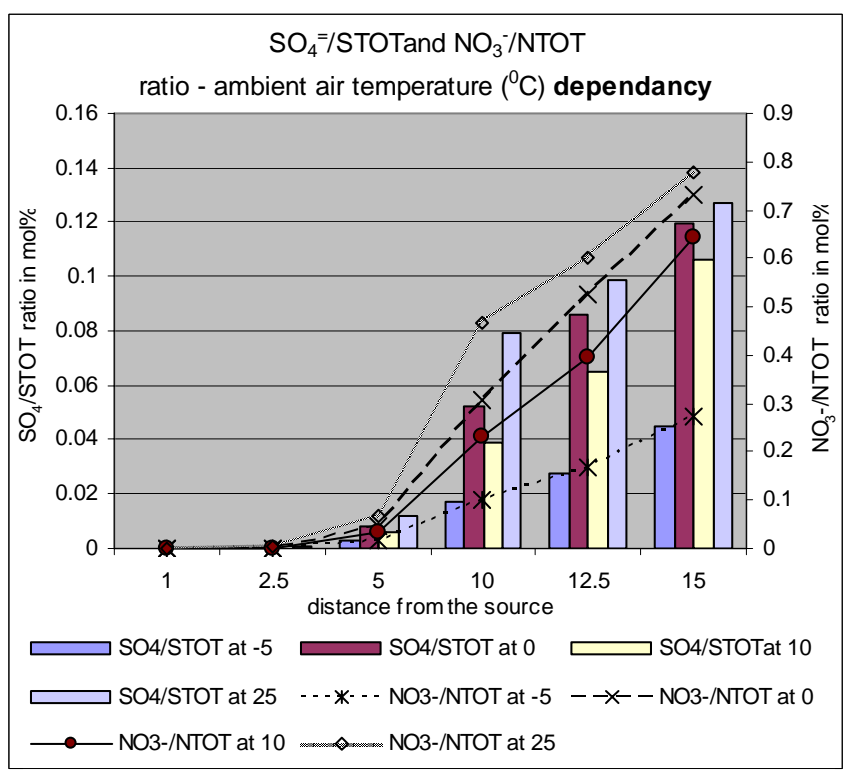

Fig. 3.

$-5^{\circ} \mathrm{C}<10^{\circ} \mathrm{C}<0{ }^{\circ} \mathrm{C}$, and is highest at $25^{\circ} \mathrm{C}$.

It is of interest to study the dependency of temperature on NOx concentrations immediately after gases' discharge. On Fig. 4, we can notice that in the starting ("zero") second, i.e. immediately after discharging the emission, the air temperature does not influence the NOx concentrations. However, after the $10^{\text {th }}$ second the rate of NOx 

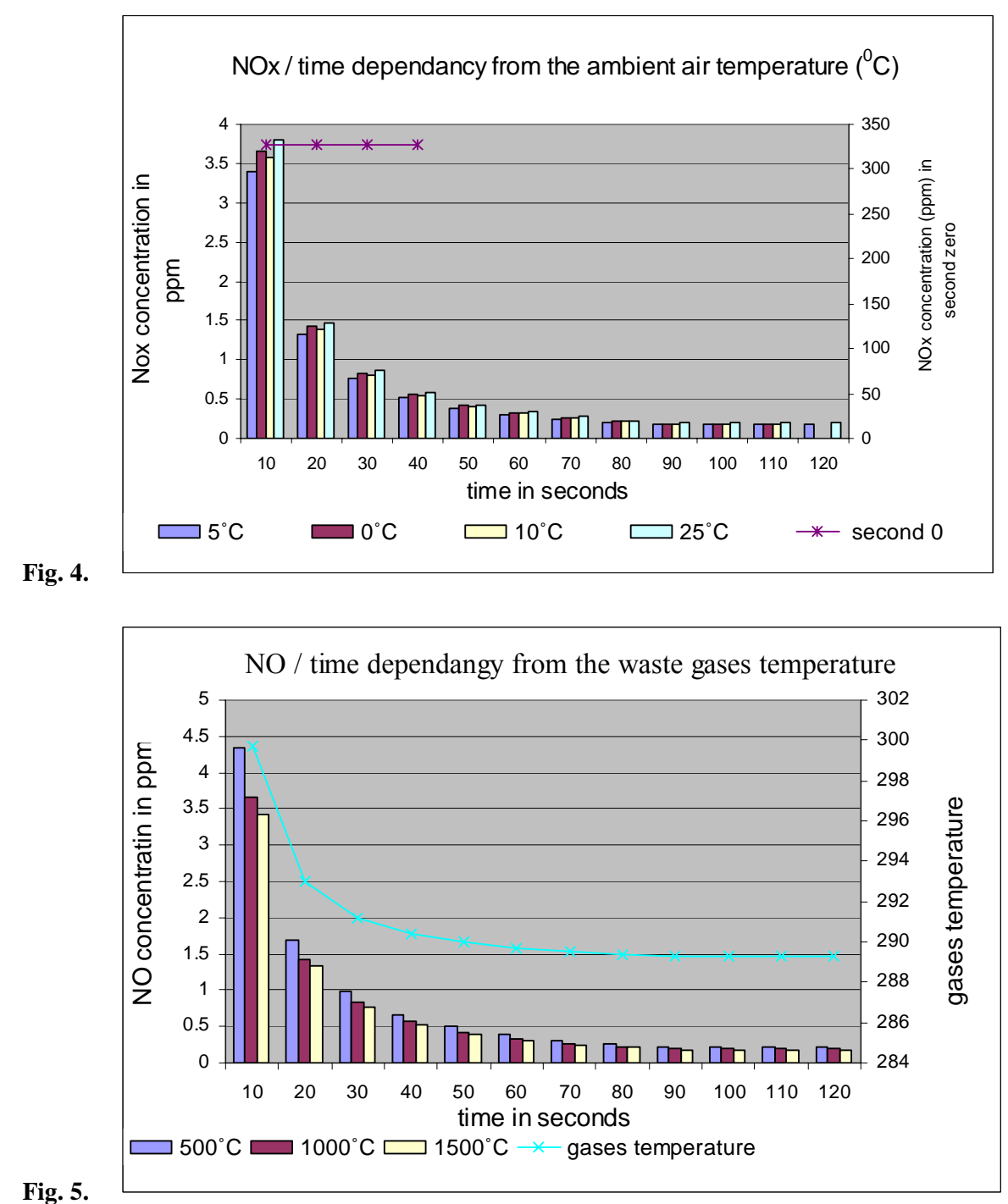

Fig. 5.

formation increases in the same order as for the ions: the lowest at $-5^{\circ} \mathrm{C}<10^{\circ} \mathrm{C}<0{ }^{\circ} \mathrm{C}$ and the highest at $25^{\circ} \mathrm{C}$.

The most essential dependency of waste gases temperature on the composition of emissions is presented on Fig. $\mathbf{5}$.

In second " 0 " (not presented on the fig.), the concentration of NO increases in parallel with increasing the waste gases' temperature. This trend is caused by the possibility of thermal oxidation to take place at higher temperatures. When nitrogen $\left(\mathrm{N}_{2}\right)$ from the fuel or the atmosphere reacts with the oxygen at high temperatures, nitrogen oxide is quickly formed.

This reaction runs at extremely high temperatures in the combustion zone.

In second " 0 " the temperature of gases is $411.66^{\circ} \mathrm{C} ; 690^{\circ} \mathrm{C}$ and $967^{\circ} \mathrm{C}$. In the $10^{\text {th }}$ second it is reaches a balance $\left(148.5^{\circ} \mathrm{C}\right)$ 
because of quick mixing with the ambient air, and from this point on the tendency is that gases which have had lower temperature now accquire the highest concentration of NO for any destination.

Summarizing the results, I can generalize the following dependencies between the physical and chemical characteristics of the ambient air and the nature of waste gases discharged from a point source (Table).

\section{REFERENCES}

1. Altshuller A.P. (1979) Atmos. Environ., 13, 16531661.

2. Briggs G.A. (1969) Plume Rise. U.S. Atomic Energy Commission Critical Review Series, TID25075, NTIS, Springfield, VA.

3. Briggs G.A. (1971) Some Recent Analyses of Plume Rise Observations. Proc. of 2nd Int. Clean Air Congress, (H.M. Englund, W.T. Berry, Eds.) Academic Press, New York, N.Y., 1029-1032.

4. Briggs G.A. (1972) Atmos. Environ., 6, 507-610.

5. Calvert J.G., Su F., Bottenheim J.W., Strausz O.P. (1978) Atmos. Environ., 12, 197-226.

6. Davis D.D., Smith D.G., Klauber J. (1974) Science, 186, 733-736.

\begin{tabular}{|c|c|c|c|}
\hline Parameter & $\mid \begin{array}{c}\text { Ambient } \\
\text { ozone } \\
\text { concen- } \\
\text { trations }\end{array}$ & $\begin{array}{l}\text { Ambient } \\
\text { air tem- } \\
\text { perature }\end{array}$ & $\begin{array}{c}\text { Waste } \\
\text { gases } \\
\text { tempe- } \\
\text { rature }\end{array}$ \\
\hline NOx concentration $(\mathrm{ppm})$ & & $\bullet$ & $\bullet$ \\
\hline $\mathrm{SO}_{2}$ concentration $(\mathrm{ppm})$ & $\bullet$ & $\bullet$ & \\
\hline $\mathrm{NO}_{2}$ /NTOT rate $(\mathrm{mol} . \%)$ & $\bullet$ & & \\
\hline $\mathrm{NO}_{3}{ }^{-} / \mathrm{NTOT}$ rate $(\mathrm{mol} . \%)$ & $\bullet$ & $\bullet$ & \\
\hline $\mathrm{SO}_{4}^{-} / \mathrm{STOT}$ rate $(\mathrm{mol} . \%)$ & $\bullet$ & $\bullet$ & \\
\hline Dependency NOx / time & & $\bullet$ & \\
\hline Dependency $\mathrm{SO}_{2} /$ time & & - & $\bullet$ \\
\hline Dependency NO / time & & & $\bullet$ \\
\hline Dependency $\mathrm{NO}_{2} \mathrm{~T} /$ time & & & $\bullet$ \\
\hline
\end{tabular}

7. Hampson R.F.Jr., Garvin D. (1978) Reaction Rate and Photochemical Data for Atmospheric Chemistry-1977. NBS Special Pub. 513, National Bureau of Standards, Washington, D.C.

8. Isaksen I., Hesstredt A., Hov O. (1978) Atmos. Environ., 12, 599-604.

9. Leighton P.A. (1961) Photochemistry of Air Pollution. Academic Press, New York, N.Y.

10. Niki H. (1974) Can. J. Chem., 52, 1397-1404. 